\title{
Forecasting the Impact of Increasing Integration of Renewable Sources in the Power Unbalance during Peak and Off-Peak Hours
}

\author{
Sérgio Faias ${ }^{1,2}$, Jorge Sousa ${ }^{1}$, Rui Castro ${ }^{3}$ \\ ${ }^{1}$ Department of Electrical Engineering and Automation, ISEL \\ Rua Conselheiro Emídio Navarro, 1, 1950-062 Lisboa, Portugal \\ Phone.: +351218317000, e-mail: sfaias@deea.isel.ipl.pt, jsousa@deea.isel.ipl.pt \\ ${ }^{2}$ Centro de Automática da Universidade Técnica de Lisboa (CAUTL), Lisboa, Portugal \\ Av. Rovisco Pais, 1049-001 Lisboa, Portugal \\ ${ }^{3}$ Instituto Superior Técnico / Technical University of Lisbon (IST/TUL), Lisboa, Portugal \\ Av. Rovisco Pais, 1049-001 Lisboa, Portugal \\ e-mail: rcastro@ist.utl.pt
}

\begin{abstract}
Environmental impacts and external dependency due to energy consumption can be minimized with integration of renewable power sources. Portugal, as well as a number of other countries, presents a sharp increase in renewable sources integration, namely in wind, solar photovoltaic, waves, biomass and small hydro.
\end{abstract}

As all renewable technologies ultimately derive energy from natural sources that vary in their availability over different timescales, the integration of larger amounts of renewable sources is becoming an increasingly important issue for the needed balance of power generation and demand.

The main objectives of this paper are the settlement of a forecast methodology to quantify power generation and demand unbalance and characterize that sort of unbalance, specially focusing on the difference between peak and off-peak periods.

Heeding the distinction between peak and off-peak hours, the results obtained show that the unbalance behaviour is particularly distinct in these periods, namely with generation shortage in peak hours and excess of generation in off-peak hours.

\section{Keywords}

Power generation, demand, power balance, renewable energy

\section{Introduction}

In the last century Human activity brought vast impact in Earth environment. Accelerated primary resources consumption and pollution are putting in risk future generations.

Environmental impacts and fuel external dependency can be minimized with integration of renewable power sources. Since 1990, the European Union (EU) has been engaged in an ambitious and till now successful plan to become world leader in renewable energy. The EU's renewable energy market has an annual turnover of 15 billion $€$ (half the world market) and employs some 300000 people. In 2001, the EU agreed that the share of electricity from renewable energy sources in the EU consumption should reach $21 \%$ by year 2010 [1], [2].

Portugal, as well as a number of other countries, presents a sharp increase in renewable sources integration, namely in power sources like wind, solar photovoltaic, waves, tidal, biomass and small hydro. It is expected that about $45 \%$ of the Portuguese electricity production will be of renewable origin by 2010 , including wind, responsible for $16 \%$ and hydropower, responsible for $23 \%$ [3].

All renewable technologies ultimately derive energy from natural sources that vary in their availability over a wide range. This fact represents a significant difference from conventional manners of operating the electrical generation system; therefore, the integration of large amounts of renewable sources in the existing system is becoming an increasingly important issue for the balancing of power generation and demand [4].

\section{Objectives and Methodology}

The main objectives of this paper are to present a forecast methodology to quantify power generation and demand unbalance and characterise that sort of unbalance, specially focusing peak and off-peak periods' specificities.

Increasing integration of renewable sources will introduce some new constraints in the Portuguese power system operation, namely it will make more difficult to match total generation and demand, mainly due to the inherent renewable power fluctuations and the significant renewable capacity that is foreseen. 
This unbalance is much undesirable whenever it occurs. However, if it occurs during peak hours, there are some alternatives to mitigate the situation, namely to release some expensive peak power stations, to operate the thermal plants at their technical minimum limits or to export to Spain. If the unbalance occurs during off-peak hours, the situation is much more difficult, because the mentioned remedy strategies are no longer possible. In this case, other alternatives should be looked upon, namely energy storage or even the much undesirable curtailment of renewable power.

Moreover, due to the fact that the demand is relatively low, it is expected that it will be precisely during off-peak hours that a more significant unbalance may occur.

Therefore, it is very important to estimate the unbalance between generation and demand and also to be able to predict its probability distribution among peak and off-peak hours.

The methodology proposed for quantifying power generation and demand unbalance, is based in subsequently steps:

1) Power system characterization

i) Generation

ii) Demand

iii) Interconnections

2) Unbalance forecast

i) Historic series scenario

ii) Historic series with dispatch intervention scenario

iii) Results analysis

\section{Portuguese Power System Characteriza- tion}

In the next paragraphs, a characterization of the Portuguese power system is briefly presented, the generation and demand being discussed separately.

\section{A. Generation}

Portuguese power system generation is based on different technologies, which include thermal, hydro and other renewable sources; no nuclear power plants are present in the generation mix.

As presented in Fig. 1, the currently installed capacity in Portugal comprise coal (14\%), natural gas $(17 \%)$, fuel oil $(13 \%)$ and diesel fuel utilities $(2 \%)$, referred as thermal technology; reservoir (18\%) and run-of-river $(15 \%)$, referred as hydro with more than $10 \mathrm{MW}$; cogeneration $(10 \%)$, wind $(8 \%)$, small hydro less than $10 \mathrm{MW}(3 \%)$, municipal solid waste $(0,7 \%)$ and biomass $(0,2 \%)$, referred as renewable.
Rising electric energy demand and environmental concerns, forces a continuous upgrade in installed capacity and changes in applied technologies.

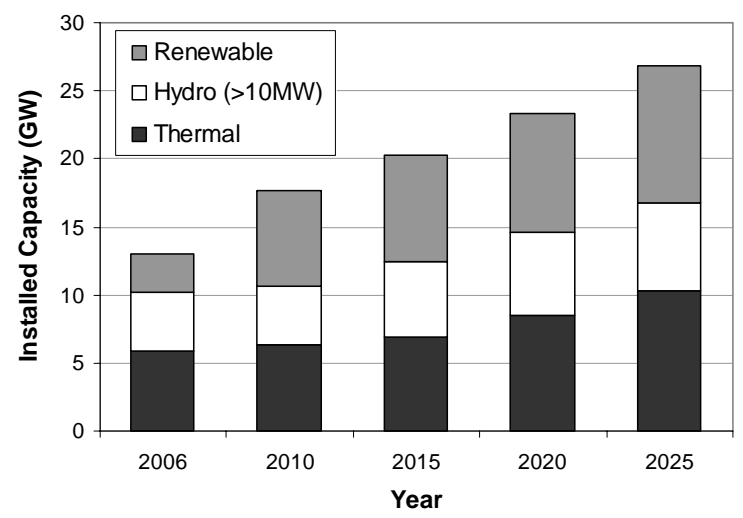

Fig. 1. Previsions for installed capacity evolution of Portuguese power system (2006-2025) [3]

Still referring to Fig. 1, a considerable increase in renewable installed capacity is expected. For the period 20062025 , previsions indicate that about $7000 \mathrm{MW}$ will be installed, with the following distribution: wind power: $4000 \mathrm{MW}$, small hydro: $1100 \mathrm{MW}$, biomass: $770 \mathrm{MW}$, solar thermal: $700 \mathrm{MW}$, municipal solid waste: $180 \mathrm{MW}$, photovoltaic: $160 \mathrm{MW}$, waves: $100 \mathrm{MW}$ and biogas: $50 \mathrm{MW}$. Additionally, some $2100 \mathrm{MW}$ of cogeneration installations (considered as some sort of renewable in Portugal as a result of its contribution for the energy efficiency improvement) are also foreseen.

Furthermore, present thermal installed capacity will experience a substantial improvement in the next 20 years. For 2006 to 2025 , installed capacity with origin in old classical thermal power plants will be out of service, namely $1256 \mathrm{MW}$ of fuel oil, $1192 \mathrm{MW}$ of coal and $165 \mathrm{MW}$ of diesel fuel. New utilities with environmental and efficiency improvements are programmed. A new capacity of $3600 \mathrm{MW}$ of clean coal technology, equipped with low sulphur and nitrate oxides emissions burners will be installed, as like as $2400 \mathrm{MW}$ of natural gas combined cycle power plants. Furthermore, $750 \mathrm{MW}$ of single cycle natural gas turbines will be set-up for peak-hours response.

Large hydropower reinforcements are also expected namely $872 \mathrm{MW}$ in case of run-of-river power plants and $1186 \mathrm{MW}$ for reservoir. Some already established reservoir power plants, as like as great part of the new ones, will be prepared for pumping, totalizing a pumping hydro installed capacity of 1344 MW. Generally, those up-grades won't be available before 2012 . 


\section{B. Demand}

Power demand varies along time and according different drivers, such as seasonality, weather condition, geographical location and normal course of human activity. As presented in Fig. 2, each one of this causes impose different time cycles variations, from annual to hourly.

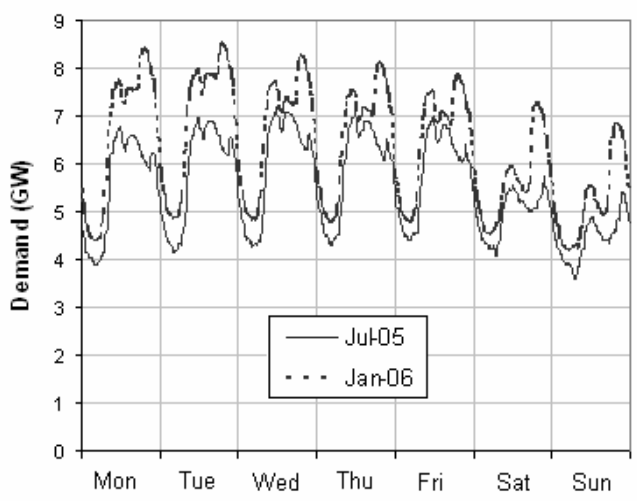

Fig. 2. Hourly, daily and seasonal variation of power demand [5]

Electricity demand has increased nearly $60 \%$ in Portugal for the last 10 years and stills shows a rising trend [6]. Fig. 3 presents previsions for annual peak power and energy consumption from 2006 to 2025 . In the next 20 years, it is expected that energy consumption will double, as well as annual peak power.

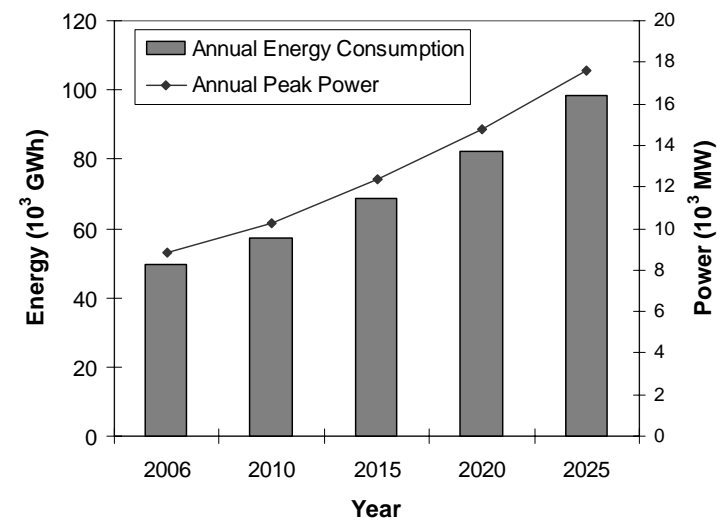

Fig. 3. Annual peak power and energy consumption previsions for Portuguese power system (2006-2025) [3]

\section{Interconnections}

The Portuguese power system is interconnected with the Spanish, allowing energy flows between them. Usually the Portuguese power system imports energy from Spain during off-peak hours for hydro-pumping and exports in peak hours [5].

The present interconnection capacity is around $1300 \mathrm{MW}$, a value that is foreseen to more than double for 2010 to 2025 .

\section{Unbalance Forecast}

The developed generation and demand unbalance forecast methodology is based on two different scenarios - historic series scenario and historic series with dispatch intervention scenario. Unbalance forecast process will employ historic series of power generation and demand, along one year, from June 2005 to May 2006, acquired by technology, in periods of 15 minutes, totalizing 35040 measurements.

\section{A. Historic Series Scenario}

Unbalance forecast using historic series scenario, intends to put in perspective the existence of the generation - demand mismatch problem.

Production estimation by technology for the years 2010, 2015, 2020 and 2025, used acquired historic data adjusted with the previsions of future new installed capacity evolution. The exceptions to this rule were technologies that are not yet mature and had no available historic data, like photovoltaic, solar thermal and waves. In this case, a constant $10 \%$ of predicted installed capacity was considered for the purposes of this study. In what concerns demand and pumping-hydro prediction, historic series corrected by evolution previsions were used.

Duration curves of power unbalance forecast using historic series scenario, for 2010 to 2025, are presented in Fig. 4. Power unbalance varies from positive (excess of generation) to negative (generation shortage).

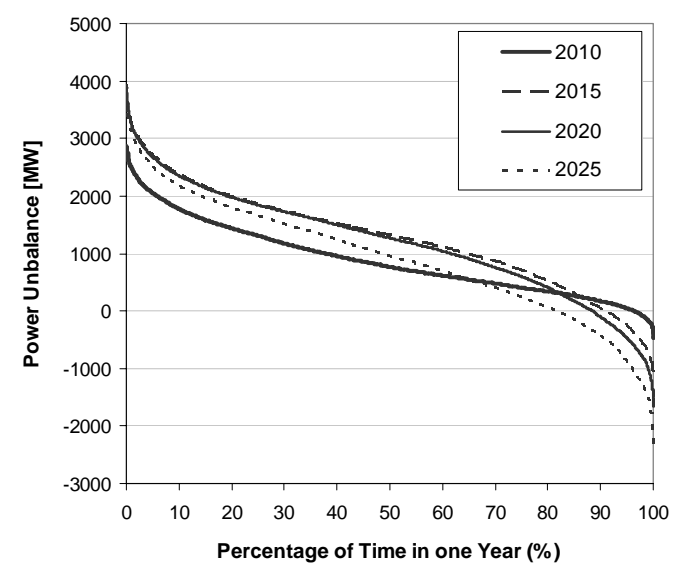

Fig. 4. Results of power unbalance forecast for a scenario where generation and demand follow the historic series

Negative values of power unbalance may be avoided by making use of installed capacity reserves. Excess of generation, on the other side, may be a problem, because below technical minimum power, thermal power plants must be turned-off. 
A possible solution to mitigate the positive unbalance would be to turn-off renewable sources. However, renewables are not generally considered as central dispatchable units in order to avoid wasting energy with origin in environmental friendly sources.

\section{B. Historic Series with Dispatch Intervention Scenario}

Historic series with dispatch intervention scenario intends to forecast the power unbalance that would result after the system operator dispatch intervention.

System operator dispatch mission is to maintain the balance between power generation and demand. For the purpose of this study, a dispatch intervention was simulated. In case of negative power unbalance, the dispatch procedure was to increase coal power plants generation, followed by natural gas generation, limited by their installed capacity. The dispatch procedure, in case of positive power unbalance, was opposite. First, the fuel oil and diesel fuel were turnedoff and then the natural gas power plants generation was reduced, followed by the reduction of the coal power plants generation. During this procedure, the coal and natural gas power plants were not turned-off, in order to avoid the start-up high costs. The decrease in their generation was limited to the technical minimum power (about $1 / 3$ of nominal power).

In spite of the system operator dispatch intervention, power unbalances are still to be expected. Monotone curves of generation and demand power unbalance for historic series with dispatch intervention scenario are presented in Fig. 5.

Generation shortages are not be expected after a dispatch intervention. However, results show that they may occur for the year 2010. This fact must be also a matter of concern, as it is relatively unexpected.

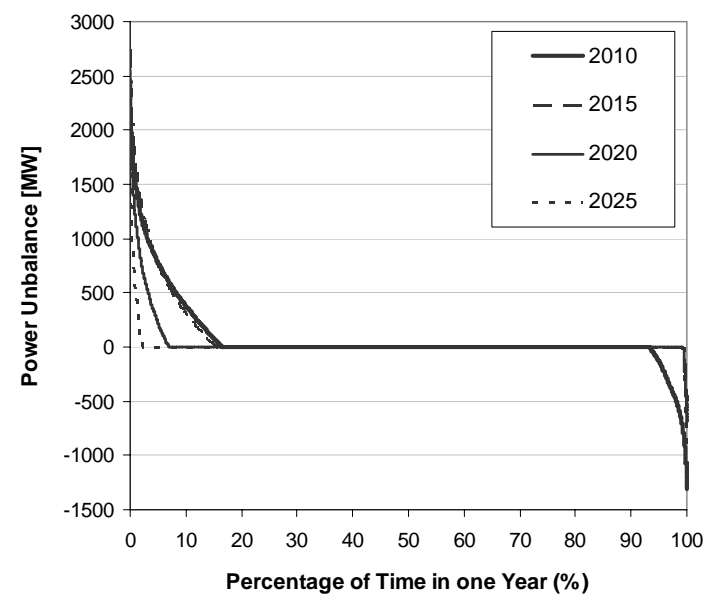

Fig. 5. Results of power unbalance for historic series with dispatch intervention scenario

\section{Results Analysis}

Next paragraphs will present the forecasted generation and demand power unbalance deep analysis. This is carried out for years 2010, 2015, 2020 and 2025, using the two scenarios described above: historic series scenario and historic series with dispatch intervention scenario. Peak and offpeak hours' specificities will be subject of special attention. In this paper, the period from 8:00 (a.m.) to 10:00 (p.m.) were considered as peak hours, whereas the remaining ones were taken as off-peak hours [7].

Fig. 6 and 7 present the daily average of instantaneous power unbalance for historic series scenario and for historic series with dispatch intervention scenario. Besides the instantaneous power unbalance annual average curve, two more results are presented: the annual average added by the standard deviation and the annual average subtracted by the standard deviation.

In the case of historic series scenario, the distinction between daily peak and off-peak hours is apparent. Along offpeak hours, short demand values plus non-dispatchable renewable generation origin a greater average power unbalance than in peak hours. Large demand and production power values in peak hours are responsible for higher power unbalances dispersion.

Historic series with dispatch intervention scenario intends to simulate the system operator actuation in order to maintain the power production and demand balance. For this case-study, daily average power unbalance is close to zero, with low dispersion, in peak hours. On the other hand, average power unbalance in off-peak hours is not easy to avoid, as a result of the thermal power plants minimum technical limits. However, in 2020 and 2025, the growth in demand induces a significant reduction in power unbalance.

The thought that power unbalance issue is distinct in peak and off-peak hours is strengthened by Fig. 8, where average power unbalances are presented.

For instance, in year 2010, the forecasted peak hours' average power unbalance for historic series scenario is about $30 \%$ lower than in off-peak hours; from 2015 to 2025, that gap slightly decreases.

As far as the dispatch intervention scenario is concerned, one may conclude that the average power unbalance approaches zero value during peak hours, which is a remarkable improvement. However, in off-peak hours a relatively short average unbalance is still to be expected, even if one should point out that it virtually tends to zero as the years go by. 


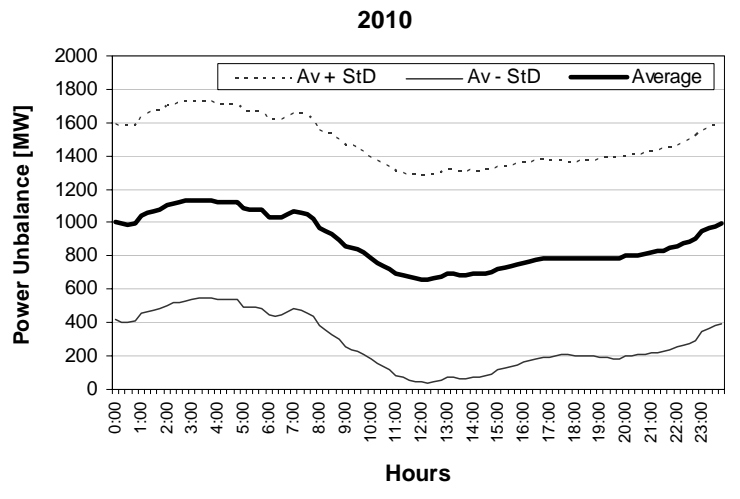

2015
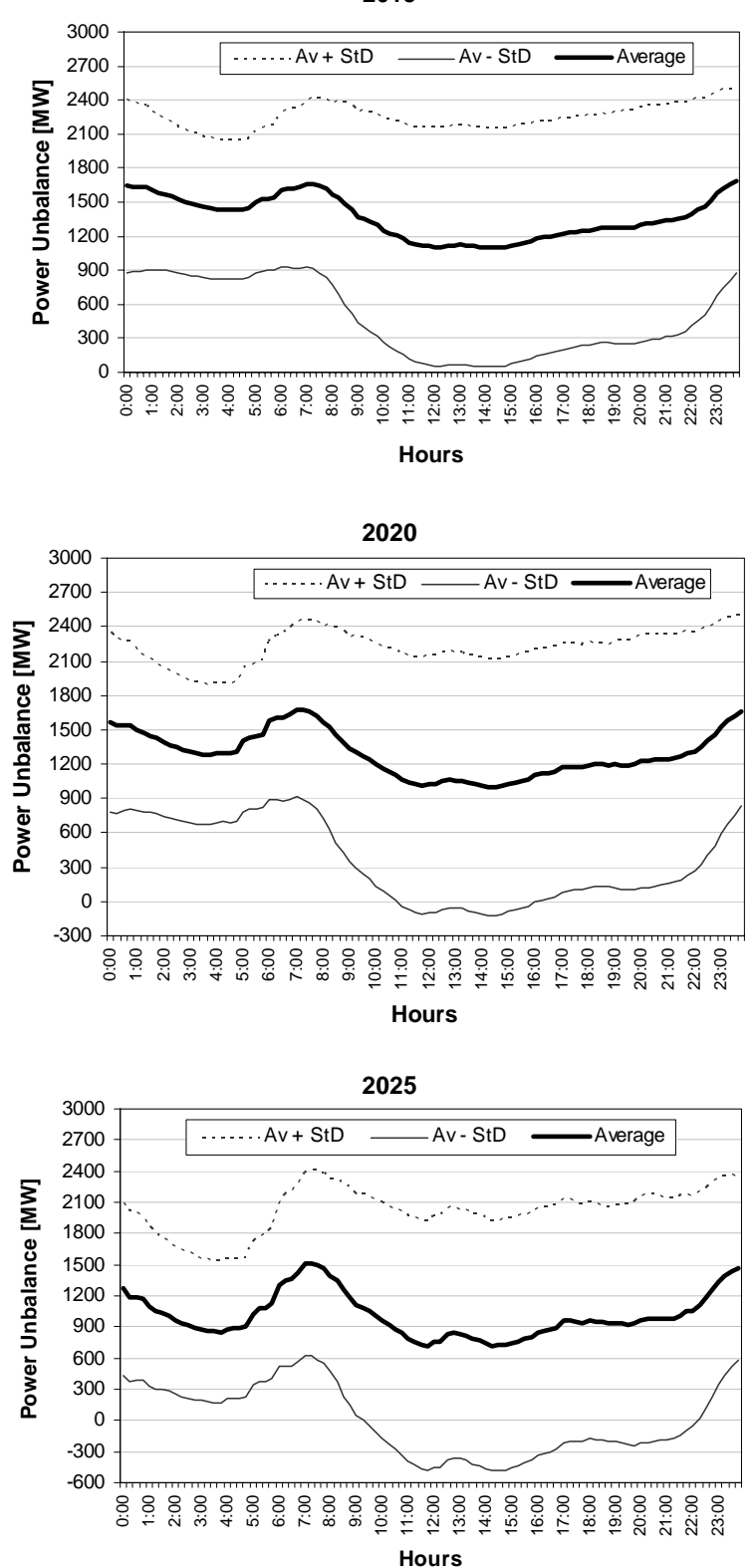

Fig. 6. Daily average of instantaneous power unbalance for historic series scenario
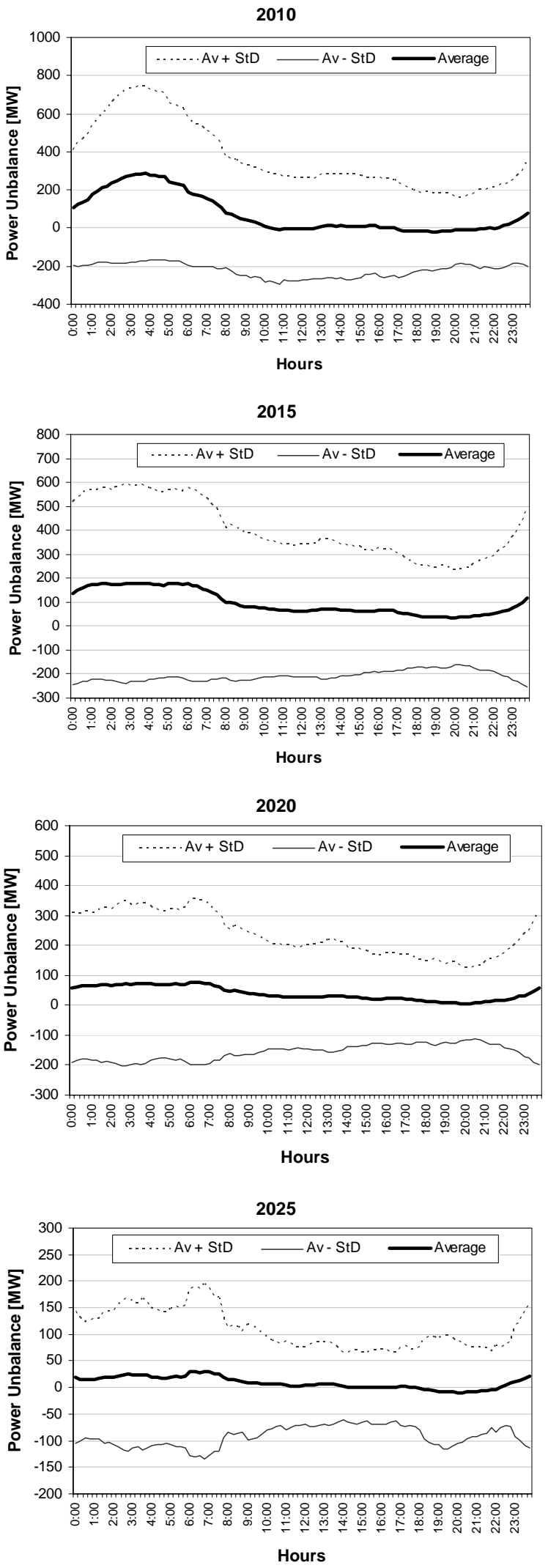

Fig. 7. Daily average of instantaneous power unbalance for historic series with dispatch intervention 


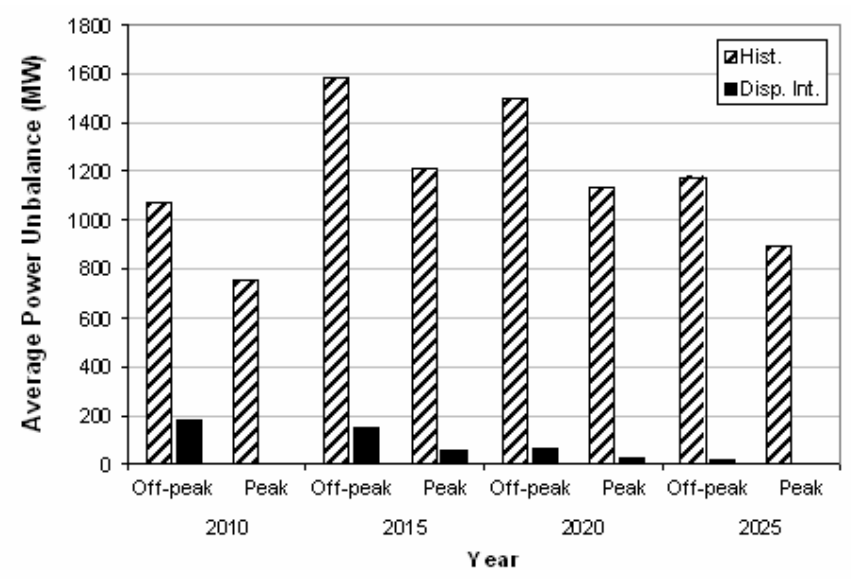

Fig. 8. Average power unbalances at peak and off-peak hours for historic series with and without dispatch intervention

Table I presents the percentage of peak and off-peak hours along which power unbalance is expected to be greater than a specified power for the historic series scenario.

For instance, results show that a generation excess of more than $1000 \mathrm{MW}$ will probably occur in 2010 , along $48 \%$ of the annual off-peak hours. At 2015 and 2020, that excess is likely to surpass $70 \%$.

In the case of peak hours, an excess of generation is also predicted. Power unbalance of more than $1000 \mathrm{MW}$ will be expected in 2015 and 2020, during nearly $50 \%$ of the annual peak hours.

TABLE I. - Percentage of Peak and Off-Peak Hours along Power Unbalance is greater than a Specified Power (Historic Series Scenario)

\begin{tabular}{|cc|c|c|c|c|}
\hline \multirow{2}{*}{$\begin{array}{c}\text { Power Unbalance } \\
\text { (MW) }\end{array}$} & \multicolumn{4}{|c|}{ Year } \\
\cline { 2 - 6 } & 2010 & 2015 & 2020 & 2025 \\
\hline$\geq 500$ & Peak Hours & $60.1 \%$ & $73.1 \%$ & $70.0 \%$ & $62.6 \%$ \\
\cline { 2 - 6 } & Off-Peak Hours & $79.5 \%$ & $93.6 \%$ & $91.0 \%$ & $78.0 \%$ \\
\hline$\geq 1000$ & Peak Hours & $30.5 \%$ & $59.2 \%$ & $56.8 \%$ & $48.6 \%$ \\
\cline { 2 - 6 } & Off-Peak Hours & $47.5 \%$ & $77.1 \%$ & $73.5 \%$ & $55.4 \%$ \\
\hline$\geq 1500$ & Peak Hours & $13.6 \%$ & $40.2 \%$ & $40.4 \%$ & $34.4 \%$ \\
\cline { 2 - 6 } & Off-Peak Hours & $23.3 \%$ & $51.0 \%$ & $46.7 \%$ & $33.5 \%$ \\
\hline$\geq 2000$ & Peak Hours & $4.5 \%$ & $22.5 \%$ & $22.9 \%$ & $18.9 \%$ \\
\cline { 2 - 6 } & Off-Peak Hours & $7.6 \%$ & $25.9 \%$ & $23.2 \%$ & $15.6 \%$ \\
\hline$\geq 2500$ & Peak Hours & $0.7 \%$ & $11.1 \%$ & $10.9 \%$ & $7.9 \%$ \\
\cline { 2 - 6 } & Off-Peak Hours & $1.2 \%$ & $10.3 \%$ & $8.8 \%$ & $5.6 \%$ \\
\hline
\end{tabular}

Table II presents the percentage of peak and off-peak hours along which power unbalance is greater or lower than a specified power for the historic series with dispatch intervention scenario.
Forecasted demand and generation power unbalance shows generation excesses that should be a matter of concern. For instance, one can observe that an excess of more than $500 \mathrm{MW}$ is likely to occur in 2010 , during $15 \%$ of the annual off-peak hours.

Still referring to the year 2010, taken as reference as it represents the "near future", an excess of more than $1000 \mathrm{MW}$ in generation is foreseen to take place during $5 \%$ of the off-peak hours.

Negative power unbalance values were supposed to be completely void, through the dispatch intervention. However, as mentioned before, some generation shortages are expected to occur in peak hours. In 2010, a generation shortage of more than $500 \mathrm{MW}$ will likely occur along $3 \%$ of the annual peak hours.

The obtained results concerning both the positive and negative mismatch between generation and demand clearly point out for a solution of innovative energy storage.

TABLE II. - Percentage of Peak and Off-Peak Hours along Power Unbalance is greater or lower than a Specified Power (Dispatch Intervention)

\begin{tabular}{|cc|c|c|c|c|}
\hline \multirow{2}{*}{\begin{tabular}{c}
\multirow{2}{*}{$\begin{array}{c}\text { Power Unbalance } \\
(\mathrm{MW})\end{array}$} \\
\cline { 2 - 6 }
\end{tabular}} & \multicolumn{4}{|c|}{ Year } \\
\cline { 2 - 6 }$\leq-500$ & 2010 & 2015 & 2020 & 2025 \\
\cline { 2 - 6 } & Peak Hours & $3.0 \%$ & $0.1 \%$ & $0.1 \%$ & $0.3 \%$ \\
\hline$\leq-250$ & Off-Peak Hours & $0.3 \%$ & -- & -- & -- \\
\cline { 2 - 6 } & Peak Hours & $6.4 \%$ & $0.5 \%$ & $0.6 \%$ & $0.7 \%$ \\
\hline$\geq 250$ & Off-Peak Hours & $0.5 \%$ & -- & -- & $0.1 \%$ \\
\cline { 2 - 6 } & Peak Hours & $5.2 \%$ & $6.7 \%$ & $3.1 \%$ & -- \\
\hline \multirow{2}{*}{$\geq 500$} & Pff-Peak Hours & $21.1 \%$ & $16.6 \%$ & $7.0 \%$ & $2.6 \%$ \\
\cline { 2 - 6 } & Off-Peak Hours & $14.7 \%$ & $9.5 \%$ & $4.8 \%$ & $1.7 \%$ \\
\hline$\geq 1000$ & Peak Hours & $1.4 \%$ & $2.4 \%$ & $0.7 \%$ & $0.1 \%$ \\
\cline { 2 - 6 } & Off-Peak Hours & $5.3 \%$ & $4.9 \%$ & $2.2 \%$ & $0.6 \%$ \\
\hline
\end{tabular}

\section{Conclusions and Perspectives}

In this paper we have presented an estimate of the future power generation unbalance in the Portuguese power system due to increasing integration of renewable sources for 2010, 2015, 2020 and 2025. This estimate addresses separately peak and off-peak hours, because it has been recognized that it is important to make such a distinction.

For that purpose, the methodology uses two different approaches - the first one, based on historic series, and the second one, which simulates the dispatch intervention of the system operator. 
Heeding the distinction between peak and off-peak hours, the results obtained show that the unbalance behaviour is particularly distinct in these periods. Low demand values associated with non dispatchable renewable generation are responsible for the greater power unbalances verified in the off-peak hours.

For historic series scenario, results show that a generation excess of more than $1000 \mathrm{MW}$ is likely to occur in 2010, along $48 \%$ of the annual off-peak hours. However, proper dispatch intervention can reduce it to some $5 \%$.

In spite of the system operator's dispatch intervention, some generation shortages are foreseen during peak hours, in the near future. In 2010, a shortage of more than $500 \mathrm{MW}$ is expected to occur along $3 \%$ of the peak hours' period.

The circumstances of generation shortage in peak hours and excess of generation in off-peak hours, take us to put in perspective an electric energy storage solution. Further developments will focus in the design of energy storage systems in order to avoid generation and demand power unbalances and maximize the renewable sources integration.

\section{References}

[1] Green Paper - A European Strategy for Sustainable, Competitive and Secure Energy, Commission of the European Communities, Brussels, March 2006

[2] Variability of Wind Power and other Renewables: Management Options and Strategies, International Energy Agency Publications, June 2005

[3] Perspectivas de Evolução do Sistema Electroprodutor Português, Período 2006-2025, REN, S.A., June 2005 (in Portuguese)

[4] Hannele Holttinen, "Impact of Hourly Wind Power Variations on the System Operation in the Nordic Countries", Wind Energy 2005; 8:197-218, 2005

[5] Estatística Diária, REN, S.A., June 2006 (in Portuguese)

[6] Direcção-Geral de Geologia e Energia, Balanços Energéticos 2004 (in Portuguese)

[7] Decreto-lei no 168/99, 19 de Maio (in Portuguese) 